$=10 \%$; DRB103 no found). NAJ ( $p<0.01)$, RS $(\mathrm{p}<0.001)$ and ESR $(p<0.01)$ were higher in EOA than in non-EOA. No differences were observed (ANOVA test) in NAJ, NEJ, RS, ESR and CRP, among the various HLA antigens found in EOA.

Conclusion EOA seems characterised by a high frequency, higher than in non-EOA, of some HLA antigens, in particular DRB103 and DRB1011, thus suggesting an immunogenetic predisposition in these patients. HLA antigens do not seem to be associated with the disease severity of EOA. However, more information may derive from an adequately long follow-up of these patients.

\section{OP0051 SYNOVITIS PREDICTS THE ARTHROSCOPIC PROGRESSION OF MEDIAL TIBIOFEMORAL KNEE OSTEOARTHRITIS (OA)}

${ }^{1} \mathrm{X}$ Ayral, ${ }^{2} \mathrm{EH}$ Pickering, ${ }^{2} \mathrm{TG}$ Woodworth, ${ }^{3} \mathrm{~N}$ Mackillop, ${ }^{2} \mathrm{~L}$ Loose, ${ }^{1} \mathrm{M}$ Dougados. ${ }^{1}$ Rheumatology B, Cochin Hospital, Paris, France; ${ }^{2} R \& D$ Global, Pfizer, Groton, USA; ${ }^{3} R \& D$ Global, Pfizer, Sandwich, UK

\subsection{6/annrheumdis-2001.418}

\section{Background}

Objectives To evaluate the prevalence of synovitis in painful medial tibiofemoral knee OA and to evaluate correlations between such synovitis and the structural severity of medial knee OA.

Methods Multicenter, prospective, one year duration study; primary painful knee OA (ACR criteria) of the medial compartment; medial joint space width $>$ or $=2 \mathrm{~mm}$; at least $10 \%$ of one cartilage surface of the medial compartment affected by superficial fibrillation or worse. Arthroscopy under local anaesthesia performed and videorecorded at entry and after one year; medial chondropathy scored by using SFA score $(0-100)$ and reader's overall assessment (VAS score $100 \mathrm{~mm}$ ); medial perimeniscal synovial scored as normal (few villi, fine vascular network), reactive (proliferation of opaque villi), inflammatory (hypervascularization and/or proliferation of hypertrophic and hyperemic villi). Progression of medial chondropathy defined by an increase in SFA and VAS scores of at least 4.5 and 8.0 after one year, respectively, as previously reported; ${ }^{1}$ assessment of severity of chondropathy by a single reader blind to chronology of paired videotapes.

Results 506 patients were enrolled and 498 completed the one year longitudinal study (mean age: $61.2 \pm 7.7$ years, female sex: 58.9\%, BMI: $30.4 \pm 4.7$, mean disease duration: $3.8 \pm 2.9$ years). The Table 1 summarises cross-sectional and longitudinal correlations between synovitis and chondropathy.

Conclusion This study suggests that synovitis is a common feature of painful knee OA, associated with more severe

\begin{tabular}{llll} 
Abstract OP0051 Table 1 & \\
\hline & $\begin{array}{l}\text { Medial perimeniscal } \\
\text { Normal }\end{array}$ & $\begin{array}{l}\text { Synovial membrane } \\
\text { Reactive }\end{array}$ & $\begin{array}{l}\text { At baseline } \\
\text { Inflammatory }\end{array}$ \\
\hline BASELINE & $\mathrm{N}=252$ & $\mathrm{~N}=145$ & $\mathrm{~N}=109$ \\
SFA score & $30 \pm 19$ & $38 \pm 20^{*}$ & $41 \pm 18^{*}$ \\
VAS score & $34 \pm 17$ & $41 \pm 19^{*}$ & $44 \pm 17^{*}$ \\
CHANGES & $\mathrm{N}=251$ & $\mathrm{~N}=144$ & $\mathrm{~N}=103$ \\
$\%$ SFA progressors & $13.1 \%$ & $14.6 \%$ & $23.3 \%^{* *}$ \\
\% VAS progressors & $13.9 \%$ & $13.2 \%$ & $30.1 \%^{* * *}$ \\
\hline
\end{tabular}

$p$-value vs Normal: ${ }^{*} p<$ or $=0.0003{ }^{* *} p=0.02{ }^{* * *} p=0.0005$. chondropathy, but it also suggests that synovitis could be considered as a predictive factor of subsequent chondrolysis.

\section{REFERENCE}

1 Ayral $X$, et al. Arthroscopic evaluation of chondropathy in osteoarthritis of the knee. J Rheumatol. 1996;23:698-706

\section{OP0052 GLUCOSAMINE SULFATE AS AN OSTEOARTHRITIS DISEASE MODIFICATION AGENT: A CONFIRMATORY, LONG-TERM, RANDOMISED, PLACEBO-CONTROLLED, INDIPENDENT STUDY}

${ }^{1} \mathrm{~K}$ Pavelka, ${ }^{1} \mathrm{~J}$ Gatterova, ${ }^{1} \mathrm{M}$ Olejarova, ${ }^{1} \mathrm{~S}$ Machacek, ${ }^{2} \mathrm{C}$ Gonzalez, ${ }^{2} \mathrm{G}$ Giacovelli, ${ }^{2}$ LC Rovati. 'Institute of Rheumatology, Prague, Czech Republic; ${ }^{2}$ Rotta Research Lab. S.p. A., Monza, Italy

\subsection{6/annrheumdis-2001.419}

Background Recent data showed that glucosamine sulfate is an osteoarthritis disease modifying agent. ${ }^{1}$ International guide-lines on clinical development of osteoarthritis drugs recommend to perform at least two independent studies to confirm the drug properties.

Objectives To confirm the effects of glucosamine sulfate as a disease modifying agent.

Methods Randomised, double-blind, placebo-controlled, study. 202 patients with knee-osteoarthritis (ACR criteria) were randomised to glucosamine sulfate $1500 \mathrm{mg}$ once-a-day p.o., or placebo for 3 years. The minimum joint space width (JSW) of the narrowest medial compartment of the tibio-femoral joint at 3 years was the study structure primary endpoint, and a secondary endpoint at 1 and 2 years. JSW was measured visually by a 0.1 $\mathrm{mm}$ graduated magnifying glass, on standardised weight-bearing antero-posterior radiographs of each knee, in full extension. Symptoms were assessed by both the WOMAC LK 3.0 version and the Lequesne indices.

Results The two study groups were comparable for demographic and disease characteristics and represented the standard primaryknee-osteoarthritis population. The placebo group presented a progressive joint space narrowing (JSN) at each year of evaluation, while glucosamine sulfate presented no average JSN at any point of evaluation. Results at 3 years are shown in the Table 1 below. Glucosamine sulfate significantly improved symptoms as measured by both the Lequesne: $(20-25 \%$ vs. $<10 \%$ with placebo) and the WOMAC (15-20\% vs. <2\%) indices. No significant differences were seen in the reported adverse events rate, while more patients on the placebo group prematurely left the study, without reaching a statistical significance.

\section{Abstract 0P0052 Table 1}

\begin{tabular}{lll}
\hline & $\begin{array}{l}\text { Placebo } \\
(\mathrm{N}=101)\end{array}$ & $\begin{array}{l}\text { Glucosamine Sulfate } \\
(\mathrm{N}=101)\end{array}$ \\
\hline JSW enrolment $(\mathrm{mm})$ & $3.59(0.16)$ & $3.97(0.14)$ \\
JSN 3 years $(\mathrm{mm})$ & $-0.19(0.05)$ & $+0.02(0.05)^{* *}$ \\
Lequesne enrolment (points) & $8.9(0.2)$ & $9.0(0.2)$ \\
$\Delta$ 3 years (points) & $-0.8(0.2)$ & $-1.7(0.2)^{* *}$ \\
WOMAC enrolment points & $30.5(1.4)$ & $30.7(1.4)$ \\
$\Delta$ 3 years (points) & $-4.9(0.8)$ & $-8.0(0.9)^{*}$ \\
\hline
\end{tabular}

Data are mean (SE). ${ }^{*} p<0.05$ and ${ }^{* *} p<0.005$ vs. placebo. Intention-to-treat (ITT) population. 